\title{
ANALISIS MODEL PEMBIAYAAN UMKM MELALUI PERAN LEMBAGA KEUANGAN MIKRO
}

\author{
Devi Anggraeni ${ }^{1}$, Erna Herlinawati ${ }^{2}$ \\ 1,2Program Studi Manajemen, STIE Indonesia Membangun, Bandung, Indonesia \\ devy.am87@gmail.com ${ }^{1}$,ernaherlinawati@inaba.ac.id ${ }^{2}$
}

\begin{abstract}
The purpose of this study is to analyze the financing model that is in line with the expectations of SMEs through the role of the Microfinance Institution (MFIs). The research method uses mix methods with descriptive-explorative type. Population 150 SMEs in the City of Bandung, West Java, with 52 samples that have received funding through MFIs and have been operating for at least 3 years. Data analysis used descriptive analysis, SWOT analysis, IFAS and EFAS.

The results of the study show that the financing model is not yet fully in line with the expectations of SMEs entrepreneurs, including financing procedures which are perceived to be complicated and interest rates are still high, so that many SMEs entrepreneurs still rely on their own capital to finance their businesses. Based on the research findings, the cooperative financing model is perceived to be suitable for SMEs, where MFIs become more optimal in carrying out their roles as facilitators of financial management, management, and marketing by involving business networks and communities. MFIs reach SMEs more so that they are easily accessible, simpler procedures, and offer cheaper interest through the use of government programs and other related financial institutions.
\end{abstract}

Keywords: financing model; SMEs ; MFIs

\begin{abstract}
Abstrak
Tujuan penelitian ini untuk menganalisis model pembiayaan yang sesuai dengan harapan pelaku UMKM melalui peran Lembaga Keuangan Mikro (LKM). Metode penelitian menggunakan mix methods dengan jenis deskriptif-eksploratif. Populasi 150 UMKM di Kota Bandung Jawa Barat, dengan 52 sampel yang telah mendapat pembiayaan melalui LKM dan telah beroperasi minimal 3 tahun. Analisis data menggunakan analisis deskriptif, analisis SWOT, IFAS dan EFAS.

Hasil penelitian menunjukkan model pembiayaan belum sepenuhnya sesuai harapan pelaku UMKM, diantaranya prosedur pembiayaan dipersepsikan rumit dan bunga masih tinggi, sehingga pelaku UMKM masih banyak yang mengandalkan modal sendiri dalam membiayai usahanya. Berdasarkan temuan penelitian, maka model pembiayaan kooperatif dipersepsikan cocok untuk UMKM, dimana LKM menjadi lebih optimal menjalankan perannya sebagai fasilitator pengelolaan keuangan, manajemen, dan pemasaran dengan melibatkan jaringan usaha dan komunitas. LKM lebih menjangkau UMKM sehingga mudah diakses, prosedur lebih sederhana, dan memberikan tawaran bunga lebih murah melalui pemanfaatan program pemerintah dan lembaga keuangan lain yang terkait.
\end{abstract}

Kata Kunci: model pembiayaan; UMKM; LKM.

Corresponding author: Email : ernaherlinawati@inaba.ac.id

History of article : Received: Desember 2018, Revised : Februari 2019, Published: April 2019 


\section{PENDAHULUAN}

Perkembangan potensi Usaha Mikro, Kecil, dan Menengah (UMKM) di Indonesia tidak terlepas dari dukungan perbankan dalam penyaluran kredit kepada UMKM. Setiap tahun kredit kepada UMKM mengalami pertumbuhan dan secara umum pertumbuhannya lebih tinggi dibanding total kredit perbankan. Penyaluran kredit oleh bank terhadap UMKM tahun 2014 meningkat $20,03 \%, 2015$ meningkat 8.22\%, 2016 meningkat $8.40 \%$, dan tahun 2017 meningkat sebesar $9.99 \%$.

Meningkatnya penyaluran kredit terhadap UMKM dalam praktiknya belum menyentuh seluruh UMKM. Persoalan klasik seputar pembiayaan dan pengembangan usaha masih tetap melekat pada UMKM. Tahun 2014, baru 30\% yang mampu mengakses pembiayaan, $76,1 \%$ mendapatkan kredit dari bank dan 23,9\% mengakses dari non bank termasuk usaha simpan pinjam seperti koperasi, artinya masih 60\%-70\% sektor UMKM belum mempunyai akses pembiayaan melalui perbankan

(Departemen

Pengembangan UMKM, 2016).

Pemerintah terus mengupayakan Pemberdayaan UMKM melalui peran Lembaga Keuangan Mikro (LKM) dalam pengembangan sektor riil. Namun peran yang dijalankan LKM masih jauh dari ideal untuk mencapai hasil optimal dalam mengakomodasi kebutuhan pengembangan ekonomi dan pengentasan kemiskinan (Tambunan, 2014).

Perlu dilakukan perubahan orientasi kredit perbankan melalui program LKM yang semula untuk kepentingan pembangunan sektoral diarahkan kepada pemberdayaan UMKM, pengembangan kelembagaan, dan kelompok. Sama halnya dengan Syarif \& Budhiningsih (2009), bahwa untuk meningkatkan kinerja UMKM, perlu dibangun sistem kelembagaan yang komprehensif untuk memperkecil jumlah instansi yang terlibat dan jenis kredit mikro yang disalurkan diantaranya KUR sehingga koordinasi menjadi mudah dan program kredit pemerintah melalui LKM dapat dialokasikan dengan baik, tepat sasaran dan dinikmati oleh UMKM

Berdasarkan permasalahan di atas, penelitian ini dilakukan untuk menggali faktor-faktor apakah yang menjadi penghambat dan pendorong UMKM serta mengevaluasi apakah LKM telah berperan dalam pemberdayaan UMKM melalui kredit mikro Tujuan penelitian ini untuk menganalisis model pembiayaan yang sesuai dengan harapan pelaku UMKM melalui peran Lembaga Keuangan Mikro (LKM), sehingga terjadi sinergitas antara kebutuhan UMKM dengan peran yang seharusnya dilakukan oleh LKM.

\section{KAJIAN PUSTAKA}

UMKM berdasarkan UU No. 20 tahun 2008 tentang Usaha Mikro Kecil dan Menengah Pasal 1 ayat 1 bahwa "Usaha Mikro adalah usaha produktif milik orang perorangan dan/atau badan usaha perorangan yang memenuhi Usaha Mikro, sebagaimana diatur dalam Undang-Undang ini." Kriteria Aset maksimal Rp50 juta dan omsetnya maksimal Rp300 juta/tahun. Kemudian Pasal 1 ayat 2 bahwa "Usaha Kecil adalah usaha ekonomi produktif yang berdiri sendiri, yang dilakukan oleh orang perorangan atau badan usaha yang bukan merupakan anak perusahaan atau bukan cabang perusahaan yang dimiliki, dikuasai atau menjadi bagian baik langsung maupun tidak langsung dari usaha menengah atau usaha besar yang memenuhi kriteria usaha kecil sebagaimana dimaksud dalam undangundang ini." Kriteria Aset di atas Rp50 jutaRp500 juta dan omsetnya di atas Rp300 jutaRp2,5 miliar/tahun.

Selanjutnya Pasal 1 ayat 3 bahwa "Usaha Menengah adalah usaha ekonomi produktif yang berdiri sendiri, yang dilakukan oleh orang perorangan atau badan usaha yang bukan merupakan anak perusahaan atau cabang perusahaan yang dimiliki, dikuasai, atau menjadi bagian baik langsung maupun tidak langsung dengan Usaha Kecil atau Usaha Besar dengan jumlah kekayaan bersih atau hasil penjualan tahunan sebagaimana diatur dalam Undang-Undang ini. Kriteria Aset di atas Rp500 juta-Rp10 miliar dengan omsetnya di atasRp2,5-Rp 50 miliar/tahun.

Kredit mikro merupakan program pemberian kredit berjumlah kecil kepada warga miskin untuk membiayai kegiatan 
produktif yang dikerjakan sendiri agar menghasilkan pendapatan, yang memungkinkan mereka peduli terhadap diri sendiri dan keluarganya (Microcredit Summit, 1997). Rosli \& Sidek (2013), menyatakan bahwa kredit mikro sebagai perpanjangan pinjaman kecil (pinjaman mikro) untuk mereka yang miskin, yang dirancang untuk memacu kewirausahaan. Kredit mikro disalurkan melalui Lembaga Keuangan Mikro.

Mengacu pada Undang-undang Republik Indonesia No.1 Tahun 2013 tentang Lembaga Keuangan Mikro, bahwa Lembaga Keuangan Mikro (LKM) merupakan lembaga keuangan yang khusus didirikan untuk memberikan jasa pengembangan usaha dan pemberdayaan masyarakat, baik melalui pinjaman atau pembiayaan dalam usaha skala mikro kepada anggota dan masyarakat, pengelolaan simpanan, maupun pemberian jasa konsultasi pengembangan usaha yang tidak semata-mata mencari keuntungan.

Pemberdayaan UMKM melalui peran Lembaga Keuangan Mikro (LKM), meliputi: (a) inisiator yang bertugas untuk memprakarsai kemajuan suatu usaha anggota; (b) sebagai fasilitator yang bertugas untuk merumuskan masalah sekaligus solusinya bagi kelompok, apakah kelompok tani, kelompok usaha kecil atau apa saja. Masalah dalam kelompok masyarakat tidak sertamerta soal dana, tetapi juga masalah pengelolaan keuangan, pengelolaan manajemen dan pengelolaan pemasaran yang selama ini menjadi kendala keberhasilan UMKM. Oleh sebab itu ada fungsi ketiga dari LKM yaitu (c) sebagai pendamping yang melakukan monitoring atau pemantauan, membimbing proses dalam pelaksanaan dan memberi penilaian serta memberi motivasi kepada anggota.

Keterlibatan LKM terhadap usaha kecil harus tuntas hingga akhirnya berhasil dan mandiri, kemudian mencari kelompok lain lagi. Dengan demikian, paradigma pemberdayaan harus melekat dengan LKM (Rofiah, 2011; Herlinawati, E., Sumawidjaja, R.N., Machmud, A., 2017).

Quartey, P. (2008), dalam penelitiannya menemukan terdapat hubungan positif akses keuangan dengan peningkatan Kinerja Perusahaan UKM di Ghana. Berbeda dengan UKM di Spanyol, saat terjadi krisis dimana kredit dari bank berkurang, banyak UKM yang menggunakan pembiayaan dari supplier. Tetapi bagi UKM yang memiliki sumber daya keuangan yang lebih baik pada umumnya tidak mengandalkan pembiayaan pemasok (Martinez, C., Garcia, P.J., \& Martinez, P. 2017).

Baker, H.K., Kumar, S., \& Rao, P. (2017), dalam penelitiannya pada UKM di wilayah Barat Laut India, menemukan UKM lebih memilih dana internal diikuti oleh pembiayaan bank terutama pinjaman jangka panjang, dana dari pemerintah dan lembaga keuangan. Di antara sumber-sumber informal, UKM lebih menyukai kredit perdagangan diikuti dengan dana dari teman-teman, keluarga, kerabat, dan pemberi dana pinjaman. Sumber pembiayaan yang paling tidak disukai adalah dana eksternal.

Bukti empiris menunjukkan terdapat kesamaan antara UKM di Inggris dan di China; UKM start-up, sebagian besar mengandalkan dukungan keuangan dari keluarga dekat. Setelah dua tahun berbisnis, adanya ketergantungan yang lebih tinggi pada tabungan sendiri dan dukungan keuangan bank dan lembaga keuangan lainnya. Berbeda saat bisnis memasuki akhir tahun ke 5, sebagian besar pemilik / manajer UKM di Inggris mengandalkan kebutuhan pinjaman terutama pada lembaga keuangan dan pada tingkat lebih rendah atas tabungan pribadi. Sebaliknya, pemilik / manajer di Cina bergantung terutama pada dukungan keuangan dari keluarga dekat mereka dan pada tingkat yang lebih rendah pada lembaga keuangan. (Hussain, J., Millman, C., \& Matlay, H., 2017)

Terdapat tiga masalah UKM di Rwanda yang berakar pada struktur tata kelola UKM yang informal dan tidak terkait dengan peran kelembagaan, rendahnya kapasitas pemilik UKM untuk mengelola bisnisnya sendiri, dan adanya persyaratan agunan menyebabkan stagnasi keuangan UKM.

Yoseva \& Syarif (2010) mengkaji manfaat bantuan perkuatan untuk UMKM. Inti dari penelitian ini adalah untuk menganalisis kinerja UMKM penerima bantuan perkuatan khususnya di bidang permodalan. Fokus kajian 
adalah pola perkreditan konvensional KSU/USP dan pola agribisnis KSU/USP. Hasil penelitian menunjukkan bahwa terjadi peningkatan kinerja dari UMKM yang mendapatkan bantuan perkuatan permodalan.

Sementara kajian Idris (2010) tentang dampak Kredit Usaha Rakyat (KUR) bagi UMKM, menemukan bahwa KUR telah memberikan dampak positif bagi UMKM, namun penyaluran KUR dinilai relatif lambat sehingga diperlukan perubahan kebijakan dalam penyaluran KUR. Penelitian selanjutnya, Ramdhansyah. \& Silalahi, S. (2013) tentang Model Pendanaan berdasarkan Persepsi UMKM. Hasil penelitian menunjukkan UMKM menghadapi banyak masalah dalam hal pendanaan bisnis, terutama dari sektor perbankan. Sehingga sumber pembiayaan yang digunakan untuk meningkatkan modal didominasi oleh sektor keuangan non-formal.

Anam, A. K. \& Nahar, A. (2015), dalam penelitiannya menyatakan LKM model kooperatif dengan prosedur relatif singkat dan biaya murah cocok untuk UMK. Adapun LKM model BPR memiliki keuntungan menyediakan jenis produk yang lebih bervariasi dan batas pinjaman dan suku bunga yang lebih besar bervariasi sehingga cocok untuk UKM. Namun LKM dalam menyalurkan pembiayaan lebih berperan pada satu fungsi sebagai sarana penyediaan dana, sementara fungsi lainnya sebagai fasilitator pengelolaan keuangan, pengelolaan pemasaran dan pengelolaan manajemen kurang berjalan sesuai harapan para pelaku UMKM, sehingga kinerja UMKM setelah mendapatkan pembiayaan meningkat pada satu aspek, yaitu finansial sedangkan non finansial tidak mengalami perubahan yang signifikan (Herlinawati, E., Sumawidjaja, R.N., Machmud, A., 2017).

\section{METODE PENELITIAN}

Penelitian menggunakan metode deskriptif eksploratif. Jenis data primer diperoleh melalui penyebaran kuesioner. Populasi dalam penelitian ini adalah UMKM di Kota Bandung, Jawa Barat, Indonesia berjumlah 150. Unit analisis berdasarkan Purposive Sampling adalah UMKM yang beroperasi minimal 3 tahun, telah mendapat pembiayaan dari Lembaga Keuangan Mikro, dan termasuk debitur kolektibilitas lancar diperoleh sampel 52 UMKM. Variabel penelitian fokus pada peran Lembaga Keuangan Mikro dalam pemberdayaan UMKM. Instrumen menggunakan kuesioner tertutup dan terbuka, hasil uji instrumen menghasilkan data valid dan reliabel. Analisis data menggunakan analisis deskriptif dan Analisis SWOT, IFAS dan EFAS (Rangkuti, 2015).

\section{HASIL DAN PEMBAHASAN}

Berdasarkan hasil tabulasi data dilakukan identifikasi terhadap kekuatan, kelemahan, peluang serta ancaman yang ada pada LKM bagi pelaku UMKM di Kota Bandung. Selanjutnya dilakukan penjabaran matriks SWOT yang digunakan sebagai suatu alternatif dalam menentukan sebuah strategi sebagaimana Tabel 1.

Hasil analisis SWOT menggambarkan tentang bagaimana peluang dan ancaman baik yang ada pada internal maupun eksternal yang dihadapi oleh UMKM yang ada di Kota Bandung, disesuaikan dengan adanya kekuatan serta kelemahan yang dimiliki UMKM itu sendiri. Strategi ini didasarkan pada suatu kombinasi antara strength-opportunity, weakness-opportunity, strength- Threats, dan juga weakness- strength. Kekuatan diantaranya muncul dari LKM lebih bisa menjangkau UMKM, bisa memberikan pinjaman yang lebih optimum, prosedur sederhana, dan biaya operasional murah.

Kelemahan berasal dari LKM terlalu fokus pada aspek penyaluran dan pengembalian dana, kurang memberikan pembinaan terhadap peningkatan kemmapuan produksi, dan kurang mendukung kegiatan pemasaran. Peluang berasal dari besarnya jumlah pelaku UMKM, 60-70\% UMKM belummengakses pembiayaan melalui perbankan, dan kebijakan pemerintah yang mendukung peningkatan kinerja UMKM. Ancaman berasal dari kondisi ekonomi yang kuran mendukung iklim usaha, tingginya bunga, dan kurangnya penguasaan teknologi.

Adapun pemetapan prioritas strategi pembiayaan UMKM di Kota Bandung 
dilakukan dengan menggunakan analisis baik itu terhadap faktor Internal maupun Eksternal, yaitu Internal Factor Analysis Summary (IFAS) dan Eksternal Factor Analysis Summary (EFAS).

Penyusunan Internal Factor Analysis Summary (IFAS) dan Eksternal Factor Analysis Summary (EFAS), dilakukan dengan: (1) Menentukan Faktor-faktor yang menjadi sebuah kekuatan dan kelemahan serta peluang dan juga ancaman UMKM, (2) Memberikan bobot dari masing-masing faktor dari skala 0,0 (tidak penting) sampai dengan 1,0 (sangat penting), dimana bobot tersebut jumlahnya tidak melebihi skor total 1,00, (3) Menghitung rating untuk masing-masing faktor dengan skala mulai dari 1 (tidak perlu), sampai dengan 4 (sangat perlu), dan (4) Menghitung total jumlah skor yang merupakan penjumlahan dari setiap pertanyaan, sebagaimana dijelaskan pada Tabel 1 dan Tabel 2.

Berdasarkan Tabel 1, perolehan nilai skor pada faktor kekuatan sebesar 1,85 sedangkan nilai skor yang ada pada faktor kelemahan sebesar 1,50, dengan total matriks IFAS sebesar 3,35. Nilai skor terbesar pada aspek kekuatan ada pada lebih bisa menjangkau pelaku UMKM sedangkan skor terkecil pada kekuatan adalah pada manajemen lebih adaptif. Pada faktor kelemahan, semua indikator memiliki nilai yang sama yaitu 0,30

Sedangkan pada Tabel 2, perolehan nilai skor pada faktor peluang sebesar 2,15 dan nilai skor pada faktor Ancaman sebesar 1,925, dengan total matriks EFAS sebesar 4,075. Dalam hal ini, total nilai skor faktor kekuatan berada di atas total nilai skor kelemahan dengan selisih nilai (+) 0,35 . Sedangkan total nilai pada faktor peluang ternyata berada di bawah nilai skor faktor ancaman dengan selisih nilai (-) 0,225.

\begin{tabular}{|c|c|c|c|}
\hline Falistor-Faktor Intermal & \multirow{2}{*}{\multicolumn{2}{|c|}{ Bobot Rating }} & \multirow[t]{2}{*}{ Nilai Skol } \\
\hline Kekuatan & & & \\
\hline a. Lebiih bisa menjandkau pelaku IMMKM & 0,15 & 4 & 0.60 \\
\hline $\begin{array}{l}\text { b. Bisa memberikan pinjaman yang lebih } \\
\text { optimum }\end{array}$ & 0,05 & 4 & 0,20 \\
\hline $\begin{array}{l}\text { c. Prosedur yang lebili sederhana bagi pelaku } \\
\text { UMKM }\end{array}$ & 0,15 & 4 & 0,60 \\
\hline d. Biaya operasional lebih murah & 0,10 & 3 & 0,30 \\
\hline e. Mandajemen lebih adantif & 0,05 & 3 & 0,15 \\
\hline Sub Total & 0,50 & & 1,85 \\
\hline Kelemahan & & & \\
\hline $\begin{array}{l}\text { a. Terlalu fokus pada aspek penyaluran dana dant } \\
\text { pengembadian danta }\end{array}$ & 0,10 & 3 & 0,30 \\
\hline $\begin{array}{l}\text { 6. Kurang memberikan pembinaan terhadap } \\
\text { peningkatan kemamplan produksi, kualitas } \\
\text { dan proses }\end{array}$ & 0,10 & 3 & 0,30 \\
\hline $\begin{array}{l}\text { c. Kurang mendukung kegiatan pemasaran dant } \\
\text { meningkatkan jaringan bissis dengan pihak } \\
\text { luar }\end{array}$ & 0,10 & 3 & 0,30 \\
\hline $\begin{array}{l}\text { d. Kurang memberikan bimbingan pengelolaan } \\
\text { keuangan }\end{array}$ & 0,10 & 3 & 0,30 \\
\hline $\begin{array}{l}\text { e. Kurang memperhatikan perbaikan manajement } \\
\text { UMKM }\end{array}$ & 0,10 & 3 & 0,30 \\
\hline Sub Total & 0,50 & & 1,50 \\
\hline Total & 1,00 & & 3,35 \\
\hline
\end{tabular}

Nilai total dari masing-masing faktor selanjutnya dinyatakan dalam rumusan matriks SWOT, yang menggambarkan nilai skor dari masing-masing kombinasi strategi kuantitatif sebagaimana ditunjukkan pada Tabel 2. 
Tabel 3. Matriks Eksternal Factor Analysis Summary (EFAS)

\begin{tabular}{|c|c|c|c|}
\hline \multirow{2}{*}{$\begin{array}{l}\text { Faktor-Faktor Eksternal } \\
\text { Peluang }\end{array}$} & \multirow{2}{*}{\multicolumn{2}{|c|}{ Bobot Rating }} & \multirow[t]{2}{*}{ Nilai Skor } \\
\hline & & & \\
\hline a. Besarnya jumlah pelaku UMKM & 0,05 & 3 & 0,15 \\
\hline $\begin{array}{l}\text { 6. Masih ada } 60 \% \text { - } 70 \% \mathrm{OMKM} \text { yang belum } \\
\text { mengakses pembiayaan melalui perbanklkan }\end{array}$ & 0,10 & 4 & 0,40 \\
\hline $\begin{array}{l}\text { c. Kebijakan Pemerintah yang mendukung } \\
\text { terhadap peningkatan kinerja UMKM }\end{array}$ & 0,10 & 4 & 0,40 \\
\hline $\begin{array}{l}\text { d. Lebih meningkatkan fleksibilitas dan } \\
\text { kemudahan akses pembiayaan kepada } \\
\text { UMKM }\end{array}$ & 0,15 & 4 & 0,60 \\
\hline $\begin{array}{l}\text { e. Meningkatkan kinerja UMKM melalui } \\
\text { pelatihan pengelolaan UMKM selain aspek } \\
\text { permodalan }\end{array}$ & 0,15 & 4 & 0,60 \\
\hline Sub Total & 0,55 & & 2,15 \\
\hline Ancaman & & & \\
\hline $\begin{array}{l}\text { a. Kondisi ekonomi yang kurang menunjang } \\
\text { iklim usaha }\end{array}$ & 0,20 & 4 & 0,80 \\
\hline $\begin{array}{l}\text { b. Masih tingginya bagi hasil / bunga kredit dari } \\
\text { lembaga keuangan }\end{array}$ & 0,075 & 3 & 0,225 \\
\hline $\begin{array}{l}\text { c. Kurangnya penguasan teknologi oleh } \\
\text { UMKM }\end{array}$ & 0,050 & 3 & 0,15 \\
\hline $\begin{array}{l}\text { d. Masih banyak syarat dari lembaga keuangan } \\
\text { yang mempersulit akses oleh UMKM }\end{array}$ & 0,125 & 4 & 0,60 \\
\hline $\begin{array}{l}\text { e. Kurangnya kemampuan kreatifitas dan } \\
\text { inovasi dalam menembus pasar oleh UMKM }\end{array}$ & 0,050 & 3 & 0,15 \\
\hline Sub Total & 0,45 & & 1,925 \\
\hline Total & 1,00 & & 4,075 \\
\hline
\end{tabular}

Berdasarkan hasil identifikasi faktorfaktor beserta penentuan selisih skor pada Tabel 1 dan Tabel 1, dapat digambarkan dalam bentuk matriks SWOT dimana faktor kekuatan dan peluang diberi nilai positif $(+)$, sedangkan faktor kelemahan dan ancaman diberi nilai (-) yang dinyatakan dalam bentuk diagram kartesius SWOT sebagaimana Gambar 1.

Analisis terhadap Model Pembiayaan UMKM sebagaimana Diagram kartesius SWOT menunjukkan model pembiayaan UMKM di Kota Bandung berada pada kuadran I atau berada pada strategi pertumbuhan (Growth), sehingga model pembiayaan sebaiknya lebih menjangkau UMKM dan lebih mempermudah akses UMKM melalui prosedur dan syarat lebih mudah, bunga lebih murah dan serta meningkatkan kemitraan dengan pihak-pihak yang berkepentingan dengan UMKM. Mengacu pada kebutuhan UMKM, maka model pembiayaan kooperatif lebih tepat diterapkan untuk UMKM, sebagaimana temuan Anam, A. K. \& Nahar, A. (2015), bahwa LKM dengan model pembiayaan kooperatif dengan prosedur relatif singkat dan biaya murah cocok untuk UMK.

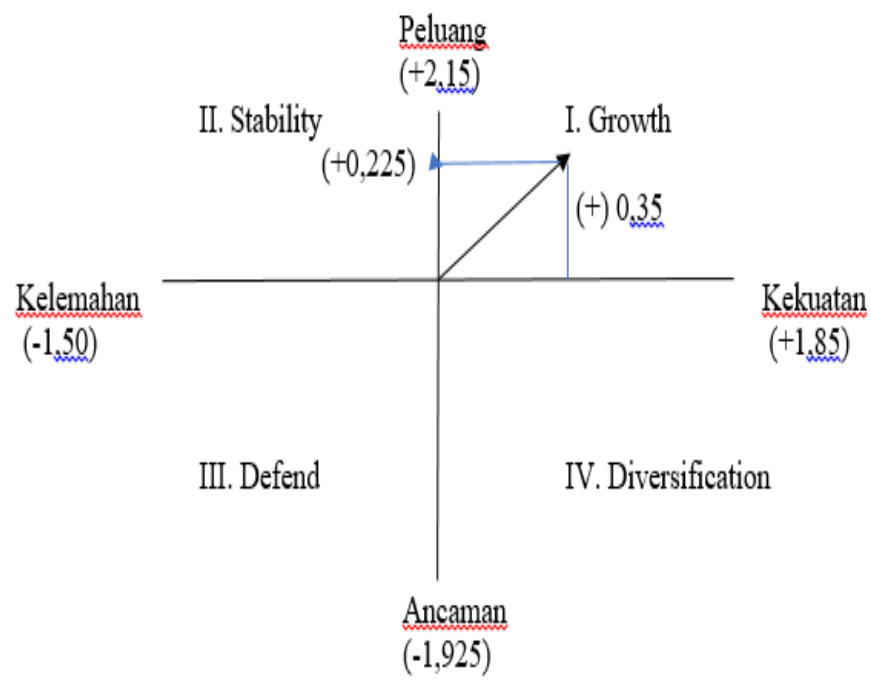

Gambar 1. Diagram Kartesius SWOT

Model pembiayaan UMKM sebaiknya memanfaatkan strategi SO karena perolehan nilai skor 4.00 yang cukup tinggi jika dibandingkan strategi lainnya, selanjutnya diikuti strategi ST dengan nilai skor sebesar 3,775, WO dengan nilai skor sebesar 3.65 dan WTO dengan nilai skor sebesar 3,425.

\begin{tabular}{lll}
\multicolumn{3}{c}{ Tabel 4. Kombinasi Strategi Kuantitatif } \\
\hline IFAS & $\begin{array}{c}\text { Kekuatan } \\
\text { (Strength)-S }\end{array}$ & $\begin{array}{l}\text { Kelemahan } \\
\text { (Weaknesss)-W }\end{array}$ \\
\hline Peluang & Strategi SO: & Strategi WO: \\
(Opportunity)-0 & $=1,85+2,15$ & $=1,50+2,15$ \\
& $=4,00$ & $=3,65$ \\
Ancaman & Strategi ST: & Strategi WT: \\
(Threat)-T & $=1,85+1,925$ & $=1,50+1,925$ \\
& $=3,775$ & $=3,425$ \\
& & \\
\hline
\end{tabular}


Untuk mendapatkan rumusan yang efektif strategi SO dengan menggunakan kekuatan (Strength) untuk memanfaatkan peluang (Opportunity), maka strategi SO dapat diimplementasikan dengan cara: (1) Memberikan pemodalan dengan tingkat suku bunga yang rendah; (2) Lebih mempermudah akses peminjaman dari Lembaga keuangan mikro; (3) Optimalisasi fasilitas pelatihan, dan (d) Peningkatan pola kemitraan.

\section{KESIMPULAN DAN SARAN}

Berdasarkan hasil pembahasan diperoleh simpulan: (1) Lembaga keuangan mikro (LKM) lebih fokus pada penyaluran dana dan pengembalian dana pada UMKM, kurang memperhatikan fungsi lainnya sebagai fasilitator dalam meningkatkan kemampuan pengelolaan keuangan, kemampuan produksi dan operasi, kualitas produk, kemampuan pemasaran dan pengembangan jaringan, serta peningkatan kinerja SDM; (2) Masih kecilnya kontribusi LKM pada UMKM disebabkan sulitnya UMKM mengakses LKM karena prosedur yang cukup menyulitkan dan bunga yang dipersepsikan masih cukup tinggi.

Mengacu pada simpulan, saran yang diajukan (1) sebaiknya LKM mengoptimalkan fungsi pelatihan yang terkait dengan pengelolaan keuangan, kemampuan produksi dan operasi serta pelatihan pemasaran dengan melibatkan jaringan usaha, (2) LKM mampu menjangkau UMKM sehingga lebih mudah diakses, prosedur yang lebih sederhana, dan memberikan tawaran biaya bunga yang lebih murah melalui pemanfaatan program pemerintah dan LKM lain yang terkait.

\section{DAFTAR PUSTAKA}

Anam, A. K. \& Nahar, A. (2015). Identifikasi model pembiayaan Usaha Kecil dan Menengah oleh Lembaga Keuangan Mikro di Kabupaten Jepara. BBM Buletin Bisnis \& Manajemen, 1 (02).

Baker, H. K., Kumar, S., \& Rao, P. (2017). Financing preferences and practices of Indian SMEs. Global Finance Journal.

Departemen Pengembangan UMKM. (2016). Profil Bisnis Usaha Mikro, Kecil dan
Menengah (UMKM). Kerjasama Lembaga Pengembangan Perbankan Indonesia \& Bank Indonesia.

Herlinawati, E., Sumawidjaja, R. \& Machmud, A. (2017). The Role of Sharia Microfinance in SMEs Business Development. In Proceedings of the 2nd International Conference on Economic Education and Entrepreneurship, 230233.

Hussain, J., Millman, C., \& Matlay, H. (2017). SME financing in the UK and in China: A comparative perspective. Journal of Small Business and Enterprise Development, 13 (4).

Idris. (2010). Dampak Kredit Usaha Rakyat (KUR) bagi UMKM. Jurnal Pengkajian Koperasi \& UKM, 5.

Martinez, C., Garcia, P.J., \& Martinez, P. (2017), SMEs access to finance and the value of supplier financing. Spanish Journal of Finance \& Accounting, 46 (4).

Quartey, P. (2008). Financing Small and Medium Enterprises (SMEs) in Ghana. Journal of African Business, 37-58.

Ramdhansyah. \& Silalahi, S. (2013). Pengembangan model pendanaan UMKM berdasarkan persepsi UMKM. Jurnal Keuangan dan Bisnis, 5 (1).

Rangkuti, F. (2015). Analisis SWOT: Teknik membedah kasus bisnis. Jakarta: Gramedia Pustaka Utama.

Republik Indonesia. (2008). Undang-undang No. 20 tahun 2008 tentang Usaha Mikro, Kecil dan Menengah.

Syarif. \& Budhiningsih. (2009). Kajian kontribusi kredit bantuan perkuatan dan mendukung permodalan UMKM. Jurnal Pengkajian Koperasi \& UKM, 4.

Tambunan, T. TH. (2014). Pentingnya keuangan mikro pengembangan UMKM di ASEAN: Bukti dari Indonesia. Jurnal of Asean Studies, 2 (2).

Yoseva, T. S. (2010). Manfaat bantuan perkuatan untuk UMKM. Jurnal Pengkajian Koperasi \& UKM, 5. 
Journal IMAGE | Volume 8, Number 1, April 2019, page 21-27 
Journal IMAGE | Volume 8, Number 1, April 2019, page 21-27 
Journal IMAGE | Volume 8, Number 1, April 2019, page 21-27 
Journal IMAGE | Volume 8, Number 1, April 2019, page 21-27 